\title{
Adipocyte proteome and secretome influence inflammatory and hormone pathways in glioma
}

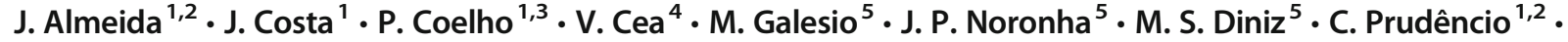 \\ R. Soares ${ }^{3,6} \cdot$ C. Sala $^{4} \cdot$ Rúben Fernandes ${ }^{1,3}$ \\ Rúben Fernandes ruben@ess.ipp.pt \\ School of Health, Polytechnic of Porto, Porto, Portugal \\ Department of Functional Biology and Health Sciences, University of Vigo, Vigo, Spain \\ Unit of Metabolism, Nutrition and Endocrinology, i3S, University of Porto, Porto, Portugal \\ CNR Neuroscience Institute Milan, and Department of Biotechnology and Translational Medicine, University of Milan, Milan, Italy \\ 5 REQUIMTE, Department of Chemistry, Faculty of Sciences and Technology, Centre for Fine Chemistry and Biotechnology, NOVA University \\ 6 Department of Biomedicine, Unit of Biochemistry, Faculty of \\ Medicine, University of Porto, Porto, Portugal
}

\begin{abstract}
Gliomas represent the most common primary malignant brain tumors in adults, with an extremely poor prognosis. Among several risk factors, lifestyle was also recently identified as a major risk factor for the development of primary glioma. In the present study, we explore the relationship between obesity and glioma in a cellular model. Thus, we have study the influence of adipocytes secretome on glioma cell line GL261. Using the 3T3-L1 adipocyte cell line, and its conditioned medium (adipokines-enriched medium), we showed that adipocyte-released factors relate with glioma angiogenic, growth, hormones and metabolic behavior by MALDI-TOF-MS and proteomic array analysis. In a first view, STI1, hnRNPs and PGK1 are under expressed on CGl. Similarly, both carbonic anhydrase and aldose reductase are even suppressed in glioma cells that grown under adipokines-enriched environment. Contrariwise, RFC1, KIF5C, ANXA2, N-RAP and RACK1 are overexpressed in GL261 cell the in the presence of the adipokines-enriched medium. We further identified the factors that are released by adipocyte cells, and revealed that several pro-inflammatory and angiogenic factors, such as IL-6, IL-11, LIF, PAI-1, TNF- $\alpha$, endocan, HGF, VEGF IGFI, were secreted to the medium into a high extent, whereas TIMP-1 and SerpinE1 were under expressed on CGl. This study discloses an interesting in vitro model for the study of glioma biology under a "obesity" environment, that can be explored for the understanding of cancer cells biology, for the search of biomarkers, prognostic markers and therapeutic approaches.
\end{abstract}

Keywords Adipo-proteomics · GL261 · Glioma · Obesity

\section{Introduction}

Gliomas, a wide term which comprises all tumors arising from the supportive tissue of the brain, represent $30 \%$ of all brain tumors and $80 \%$ of all malignant brain tumors. They are the most common primary malignant brain tumors in adults (Parkin et al. 2002; Ostrom et al. 2014). Prognosis is extremely poor, with a median survival time of approximately 12 to 15 months and is almost invariably fatal (Patrick and Kesari 2008). This tumor represents about $12-15 \%$ of all primary brain tumors and about $60-75 \%$ of all astrocytomas. Gliomas increase in frequency with age, and affect preferentially men (Patrick and Kesari 2008; Chen et al. 2012; Huse et al. 2013). Genetic factors in glioma etiology are poorly understood; less than $5 \%$ of glioma cases are familial in origin, with only a few described by rare genetic syndromes (Bainbridge et al. 2014). Gliomas are heterogeneous and are typically classified according to World Health Organization tumor grade, and also classified on the basis of cellular lineage: astrocytic, oligodendroglial, and mixed tumors (Luisa et al. 2012). 
In 2001, different studies from the International Agency for Research into Cancer (IARC) and the World Cancer Research Fund (WCRF) have reported a relationship and established a link between obesity and cancer risk (Roberts et al. 2010; Khandekar et al. 2011). Excess adiposity is related with an increase the incidence and/or death rates from a wide variety of human cancers, being the most common colon, rectum, esophagus, kidney, pancreas, gallbladder, ovary, cervix, liver, prostate and certain hematopoietic cancers (Pi-Sunyer 2002; Calle and Thun 2004; Roberts et al. 2010; Prieto-Hontoria et al. 2011; Khandekar et al. 2011). Overweight and obesity are important risk factors for developing cancer and also for cancer related mortality (van Kruijsdijk et al. 2009; Wolin et al. 2010). It is important to understand the pathophysiological mechanisms involved in the link between obesity and cancer, in order to target future preventive and therapeutic strategies for cancer in obese people (van Kruijsdijk et al. 2009).

Despite its high morbidity, the etiology of glioma remains largely unknown. Among several risk factors, lifestyle was also recently identified as a major risk factor for the development of primary glioma (Benson et al. 2008). Consequently, there might be a relationship between the increase and dysfunction of adipose tissue. Obesity, favored by the modern lifestyle, acquired epidemic proportions nowadays, and accelerated weight gain, in adults, is associated with increasing incidence of all central nervous system tumors, mostly glioma (Young and Van Brocklyn 2007). At the present time, it is not clear which factors might be involved in this relation. Genes that influence obesity are highly expressed in the brain and could also mediate glioma susceptibility (Benson et al. 2008; Moore et al. 2009). Some studies analyzed body weight in relation to survival in glioma demonstrating higher death rates in patients with an excess body weight (Siegel et al. 2013). Obesity, and in particular visceral obesity, plays a major role in the pathogenesis of several metabolic disorders (Calle et al. 1999). Recently two large sample studies have established that obesity has no clear relationship with the occurrence of glioma (Wiedmann et al. 2017; Disney-Hogg et al. 2018).

Development of obesity is also associated with substantial modulation of adipose tissue (AT) structure, involving adipogenesis, angiogenesis, and extracellular matrix remodeling (Costa et al. 2004; Lijnen 2008). Thus, AT can trigger blood vessel formation, and in turn AT endothelial cells promote pre-adipocyte differentiation. Angiogenesis, the physiological process involving the growth of new blood vessels from existing vasculature, plays a central role in growth and development of both normal and malignant tissues (Costa et al.; Carmeliet 2003). Angiogenesis is required for AT expansion, as well as for cancer progression and metastization (Costa et al. 2007). Antiangiogenic therapy has been a widely used strategy to fight tumor growth, and recently has also been acknowledged as a potential therapeutic intervention for obesity (Costa et al. 2007; Pirraco et al. 2010).

Furthermore, and concerning lipid diet content, evidence demonstrates that lipid metabolism is dysregulated in obesity and there might be a common pathway between excess nutrients and inflammation to increased metabolic risk (Young and Van Brocklyn 2007; Yin et al. 2008). Increase in lipolysis in AT leads to elevation in free fatty acids (FFA) in plasma and contribute to fat deposition in liver and skeletal muscle, which may promote systemic insulin resistance through several mechanisms, such as induction of oxidative stress through incomplete oxidation and inflammatory responses. However, the cause of the adipocyte malfunction remains to be identified in obesity(Yin et al. 2008).

AT is also recognized by its endocrine function as producer of biological mediators (van Kruijsdijk et al. 2009; Wolin et al. 2010). There are several cytokines regarding cell proliferation, angiogenesis, cytoskeletal rearrangement and survival. Some receptors and signaling pathways associated have revealed to stimulate growth and invasiveness capacity of glioma cells, whereas others have been correlated to glioma cell proliferation blockage (Young and Van Brocklyn 2007; van Kruijsdijk et al. 2009; Roberts et al. 2010). The mechanisms underlying the associations between energy balance and cancer risk should be clarified.

The present study aims to develop an in vitro rodent model for the study of the influence of adipokines secreted by adipose tissue in glioma biology. We propose a model in which GL261 cells, a mouse glioma cell line, is cultured in the presence or absence of 3T3-L1 mature adipocytes conditioned medium. The 3T3-L1 pre-adipocytes were differentiated under controlled experiments and the adipokines and inflammation chemokines pattern expression were examined by proteome microarrays in the mature adipocytes conditioned medium were grown.

\section{Materials and methods}

The protein expression was accessed by means of bidimensional polyacrylamide gel electrophoresis under denatured conditions (2D-PAGE) followed by mass spectrometry analysis of the interest spot. The spots were analyzed by matrix assisted laser desorption ionization time-of-flight/ mass spectrometry (MALDI-TOF-MS). The nonconditioned glioma cells served as the control group for the conditioned glioma cells. We have used the mature adipocytes secreted adipokines (secretome) and enriched the GL261 medium, followed by analysis of the proteins on GL261 on a 2-dimensional proteomic gel approach, so different spots could be studied by means of mass spectroscopy. 


\section{Chemicals}

The reagents acetonitrile, iodoacetamide (IAA), dldithiothreitol (DTT) $(99 \% \mathrm{w} / \mathrm{w})$ and trypsin from porcine pancreas (proteomics grade) were purchased from Sigma (Steinheim, Germany). Formic acid puriss for mass spectrometry $(\geq 98 \%)$, ammonium bicarbonate $(>99.5 \% \mathrm{w} / \mathrm{w})$ and the matrix assisted laser desorption ionization MALDI matrix $\alpha-$ Cyano-4-hydroxycinnamic acid ( $\alpha$-CHCA) puriss for MALDI-MS were from Fluka (Buchs, Switzerland). Trifluoroacetic acid (TFA, 99\% v/v) was from Riedel-deHaën (Seelze, Germany). ProteoMass Peptide MALDI-MS Calibration Kit (MSCAL2) from Sigma was used as mass calibration standard for MALDI-TOF-MS.

\section{Cell culture}

For the current work 3T3-L1 (purchased from American Type Culture Collection) and GL-261 (gently given by Prof. Pedroso Lima, CNC, Coimbra, Portugal) mouse cell lines were used. 3T3-L1 and GL-261 cells were cultured in DMEM (Dulbecco's Modified Eagle's Medium with $4.5 \mathrm{~g} / \mathrm{L}$ Glucose \& L-Glutamine, without Sodium Pyruvate. Santa Cruz Biotechnology, Inc.), supplemented with 10\% FBS, and 1000 units $/ \mathrm{mL}$ gentamycin solution, maintained in $\mathrm{T}-25$ tissue culture flasks in $5 \% \mathrm{CO}_{2} / 95 \%$ air at $37{ }^{\circ} \mathrm{C}$ in a humidified incubator.

\section{Adipocyte differentiation and conditioned medium collection}

3T3-L1 pre-adipocytes were propagated and allowed to reach confluence. After 2 days (day 0), the differentiation was initiated by addition of a hormonal mixture composed of $2 \mu \mathrm{M}$ insulin, $1 \mu \mathrm{M}$ dexamethasone and $0.25 \mathrm{mM}$ isobutylmethylxanthine. Three days after (day 3 ), the induction medium was replaced by complete medium supplemented with insulin only. At day 6 cultures were washed twice in phosphate buffered saline and incubated in serum-free medium. After $24 \mathrm{~h}$ (day 7), medium was harvested from the adipocytes cultures, spun for $3000 \mathrm{~g}$ for $5 \mathrm{~min}$ and the supernatant (mature adipocytes conditioned medium) was stored at $-80{ }^{\circ} \mathrm{C}$ for the subsequent treatments. This conditioned medium is rich in adipokines which are globally referred as secretome.

Afterwards, Glioma cells were divided in two distinct groups. On one hand, glioma cells GL-261 were grown under the influence of the mature adipocytes secretome were designated conditioned glioma cells (CGl). On the other hand, the control group consisted in the glioma cells cultured in the absence of 3T3-L1 conditioned medium and was designated as non-conditioned glioma cells (NCGl).

\section{Sample preparation for 2D-PAGE}

Sample preparation for 2D-PAGE was performed according to published procedures with minor modifications (Verpelli et al. 2010). The cells were manual detached from the flask and were mechanically lysed at $4{ }^{\circ} \mathrm{C}$ in lysis solution [CHAPS $4 \%, 5 \mathrm{mM}$ Tris, $\mathrm{pH} 8.8,0.05 \%$ protease inhibitor cocktail (Sigma)] using a glass potter, and the samples were centrifuged at $2000 \mathrm{~g}$ for $15 \mathrm{~min}$ at $4{ }^{\circ} \mathrm{C}$ in order to eliminate aggregates. The protein concentrations in each sample were measured by means of a DC Bio-Rad assay. A total of $900 \mathrm{mg}$ of protein from each sample was precipitated with cold acetone and resuspended in thiourea buffer ( $7 \mathrm{M}$ urea, $2 \mathrm{M}$ thiourea 2\% CHAPS, 2\% ASB14, 5\% glycerol, $40 \mathrm{mM}$ DTT, 4 mM TCEP, 1\% 3-10 IPG buffer, Amersham), and the samples were mixed overnight at $4{ }^{\circ} \mathrm{C}$ in the dark and clarified by centrifugation at $16000 \mathrm{~g}$ for $15 \mathrm{~min}$ at $4{ }^{\circ} \mathrm{C}$. The supernatant was first separated by isoelectric focusing over a $\mathrm{pH}$ range of 3-10 using precast first-dimension drystrip 3-10 NL $11 \mathrm{~cm}$ (Bio-Rad) following a multi-step protocol for 90,000 Vht (Protean IEF Cell, BioRad). The first-dimension strip was equilibrated in $50 \mathrm{mM}$ Tris, $\mathrm{pH} 8.8,6 \mathrm{M}$ urea, $30 \%$ glycerol, $2 \%$ SDS plus $16 \mathrm{mM}$ DTT for $20 \mathrm{~min}$, and then plus $25 \mathrm{mM}$ iodioacetamide for $15 \mathrm{~min}$, and loaded on a midi format $(11 \mathrm{~cm})$ 9-16\% acrylamide gel to separate the proteins by molecular weight. Second-dimension runs were performed using BioRad Midi Cell at $30 \mathrm{~V} 1 \mathrm{~h}, 300 \mathrm{~V} 4 \mathrm{~h}$ at a constant temperature of $18{ }^{\circ} \mathrm{C}$. Protein spots were revealed using home-made blue Coomassie staining, and the gel images were acquired by means of an Image scanner at 300 DPI resolution and analyzed using Image2D Master Platinum software (both from Amersham).

At least three gels per condition were included in the analysis. Normalized spot volume values were studied using SPSS software version 13.0 for statistical analysis (SPSS Inc.). In brief, the data for each spot match set were analyzed using a box-plot test in order to eliminate outliers, a K-S test to check normal distribution, an $\mathrm{F}$ test to analyze the variance, and finally Student's $T$ test to compare the mean values, which were considered significant for a $P$ value cut off of 0.01 .

\section{In-gel protein digestion}

In-gel digestion of the excised proteins with trypsin was performed according to published procedures with minor modifications (Rosenfeld et al. 1992; Shevchenko et al. 2006; Gundry et al. 2009). Protein spots were destained for $10 \mathrm{~min}$ with a solution of acetonitrile $50 \%(\mathrm{v} / \mathrm{v})$ in $25 \mathrm{nM} \mathrm{NH}_{4} \mathrm{HCO}_{3}$ and mixed vigorously using a vortex. After removal of the destaining solution, gel pieces were washed with water for $10 \mathrm{~min}$ using vigorous vortexing. This step was repeated twice. Afterwards, the gel pieces were dehydrated in acetonitrile for $10 \mathrm{~min}$, which was then removed, and the gel pieces 
were placed to dry in a vacuum centrifuge. Reduction of protein disulfide bonds was performed with a solution $10 \mathrm{mM}$ of dithiotreitol (DTT) in $25 \mathrm{mM} \mathrm{NH}_{4} \mathrm{HCO}_{3}$, for $15 \mathrm{~min}$ at $60^{\circ} \mathrm{C}$. After cooling to room temperature for about $15 \mathrm{~min}$, the DTT solution was replaced with a solution $110 \mathrm{mM}$ of iodoacetamide (IAA) in $25 \mathrm{mM} \mathrm{NH}_{4} \mathrm{HCO}_{3}$. Incubation with the alkylation agent was performed for $35 \mathrm{~min}$ at room temperature in the dark. After reduction and alkylation steps, the gel pieces were submitted once more to the washing and dehydration procedure with water and acetonitrile, in the same way as described above. Subsequently, the gel pieces were completely dried in a vacuum centrifuge. The dried protein spots were incubated with a solution of trypsin $25 \mathrm{ng} / \mu \mathrm{L}$ in $12.5 \mathrm{mM} \mathrm{NH}_{4} \mathrm{HCO}_{3}$ in an ice bath for $30 \mathrm{~min}$ to rehydrate the gel and to allow enzyme penetration into it. In-gel protein digestion was performed at $37^{\circ} \mathrm{C}$ overnight. After collecting the supernatant to clean vials, further peptide extraction was performed by addiction of a solution of trifluoroacetic acid $0.1 \%(v / v)$ in acetonitrile $50 \%(v / v)$ to the gel pieces and incubation at room temperature with shaking for $10 \mathrm{~min}$. This step was repeated twice. All extracts were pooled and evaporated to dryness. The samples were re-suspended with $10 \mu \mathrm{L}$ of trifluoroacetic acid $0.1 \%(v / \mathrm{v})$.

\section{MALDI-TOF-MS analysis}

Prior to MALDI analysis, the sample was mixed with an equal volume of the MALDI matrix solution, $10 \mathrm{mg} / \mathrm{ml} \alpha$-CHCA in trifluoroacetic acid $0.1 \%(\mathrm{v} / \mathrm{v})$ and acetonitrile $50 \%(\mathrm{v} / \mathrm{v})$. An aliquot of the sample/matrix solution $(0.5 \mu \mathrm{L})$ was handspotted onto the MALDI sample plate and the sample was allowed to dry. The mass spectrometric analyses were performed using the Applied Biosystems MALDI-TOF-MS system model Voyager-DE PRO Biospectrometry Workstation equipped with a nitrogen laser radiating at $337 \mathrm{~nm}$ (Applied Biosystems, Foster City, USA) and the laser intensity was set just above the threshold for ion production. MALDI mass spectra were acquired in positive ion reflectron mode, with an accelerating voltage of $20 \mathrm{kV}$, a grid voltage of $15 \mathrm{kV}$, $0.4 \mathrm{~V}$ of guide wire and an ion extraction delay of $100 \mathrm{~ns}$. The MS spectra for each sample were based on the average of 700 laser shots per spot with an acquisition rate of $2 \mathrm{~ns}$. MS acquisition data was calibrated externally using the ProteoMass Peptide MALDI-MS Calibration Kit.

\section{Data analysis and database searching}

All data were processed using DataExplorer 4.5 software from Applied Biosystems. Peptide Mass Fingerprint (PMF) data were used to search for candidate proteins using the MASCOT database search (http://www.matrixscience.com) engine. SwissProt database was selected by default for all Mascot searches. NCBInr database was used each time no significant identification was obtained with SwissProt. Database searches were, by default, performed with no taxonomy restriction and allowing up to a maximum peptide mass tolerance of $100 \mathrm{ppm}$. The number of allowed missed cleavages for trypsin was set to one. Carbamidomethylation of cysteine and methionine oxidation were selected as fixed and variable modifications, respectively. In order to provide accurate results, protein identification was considered positive for MASCOT protein scores higher than $77(p<0$. 01 ) that present a minimum of 4 peptides matching.

\section{Proteome profiler ${ }^{\mathrm{TM}}$ array assay}

Determination of relative levels of pre-selected mouse adipokines in conditioned and non-conditioned GL261 cell cultures was performed by using Mouse Adipokine Array Kit (R\&D Systems Europe, UK). Cells were rinsed with PBS before Lysis Buffer solubilization at, approximately, $1 \times 107 \mathrm{cells} / \mathrm{mL}$. Then, they were resuspended and rocked at $4{ }^{\circ} \mathrm{C}$ for $30 \mathrm{~min}$, following a microcentrifugation at $14,000 \mathrm{x} g$ for $5 \mathrm{~min}$. After supernatant transfer into a clean test tube, proteins were quantified a total protein assay. Array Procedure was performed according to manufacture instructions (Catalogue Number ARY024). Data analysis was based on pixel densities on developed X-ray film collected and analyzed using Gel-Doc XR (Bio-Rad@ Laboratories), acquired by Image Lab Software 5.2.1 (Bio-Rad@ Laboratories) then quantified by ImageJ 1.49 (NIH, USA).

\section{Computational biology databases and in silico cancer signaling analysis}

In order to analyze the relationship between the characteristics of glioma cells and molecules secreted by adipocytes we have used The Cancer Genome Atlas (TCGA) and REATOME to further evaluate the expression of molecular pattern profiles.

TCGA is a collaboration between the National Cancer Institute (NCI) and the National Human Genome Research Institute (NHGRI) with comprehensive, multi-dimensional information of fundamental genomic changes in 33 types of cancer. Regarding TCGA, we have inquired the Brain Lower Grade Glioma cohort (TCGA-LGG project, $n=516$ ) database from Research Network (www.cancergenome.nih.gov).

We have also upload the orthologs genes coding for the referred proteins into REACTOME (https://reactome.org/) to screen their involvement in human glioma cancer cells. This platform can be used to interpret the results of highthroughput experimental genomic studies and by systems biologists to building up predictive models of normal and disease variant pathways (Fabregat et al. 2018). Reactome pathway, reaction and molecules pages extensively cross-reference to over 100 different online bioinformatics resources, 
including NCBI Gene, Ensembl and UniProt databases, the UCSC Genome Browser, ChEBI small molecule databases, and the PubMed literature database.

\section{Statistical analysis}

The differences in expression of proteins between glioma medium and CGl by Proteome Profile Microarray were analyzed by 2-way ANOVA for multiple comparisons with Prism Graphpad. $P$ values of $<0.05$ were considered statistically significant. MALDI-TOF-MS was conducted by T-test at $\mathrm{P}$ value cut off of 0.1 using default parameters with Prism Graphpad.

\section{Results and discussion}

In order to understand which adipocyte secreted proteins potentially influenced glioma tumor behavior, we analyzed the protein expression of glioma cells conditioned medium obtained from adipocytes cultures, by means of bidimensional polyacrylamide gel electrophoresis under denatured conditions (2D-PAGE) followed by mass spectrometry analysis of the selected spots. These spots were analyzed by matrix assisted laser desorption ionization time-of-flight/mass spectrometry (MALDI-TOF-MS). The non-conditioned glioma cells (NCGl) were used as the control group for the conditioned glioma cells (CGl).

\section{Differentially expressed proteins}

Eleven differentially expressed spots were identified among the 1192 matched protein spots. Its detailed information is presented in Table 1.

The 5 over-expressed proteins found on the CG1 cells. RFC1 corresponds to spot-1 with 9.38 isoelectric point, 126,705 relative molecular mass and presenting a 2.32 ratio. KIF5C corresponds to spot-2, with 5.86 isoelectric point, 109,777 relative molecular mass and 2.91 ratio. ANXA2 corresponds to a spot-3 protein spot, with 7.55 isoelectric point, 38,937 relative molecular mass and 2.23 ratio. NRAP, corresponds to spot-4, with 9.34 isoelectric point, 196,716 relative molecular mass and 2.82 ratio. RACK 1 , corresponds to spot5 , with 7.60 isoelectric point, 35,511 relative molecular mass and 2.07 ratio (Table 1). The 3 spots significantly underexpressed in CGl corresponding to 3 proteins identified as follows: STI1, corresponds to spot- 6 and it presents a 6.4 isoelectric point, 63,170 relative molecular mass and 0.33 ratio; hnRNP L, corresponds to spot-7 spot, with 8.33 isoelectric point, 64,550 relative molecular mass and 0.66 ratio; PGK1, corresponding to spot- 8 , with 8.02 isoelectric point, 44,921 relative molecular mass and 0.4 ratio.

Only 2 spots were present in NCGl control group were Aldose Reductase, corresponds to spot-9, with 6.71 isoelectric point, 36,052 relative molecular mass, and carbonic anhydrase, corresponds to spot-10, with 6.45 isoelectric point, 30,124 relative molecular mass.

The only spot present in the CGl was Citrate Synthase that corresponds to spot-11, with 8.72 isoelectric point and 51,988 of relative molecular mass.

\section{Expression proteomic profile of GL261 conditioned medium}

Intending to further elucidate the involvement of adipose secretome in glioma, we evaluated the profile of GL261 under conditioned medium (CGL). The medium proteome is a desirable sample due to their accessibility and representability due, in part, to the wide dynamic range of protein concentrations, which lead to the discovery of new protein markers (Fig. 1).

As illustrated in Fig. 1 different secretion patterns of numerous growth-factors, adipokines, cytokines and angiogenesis-related molecules; were found between the different media. Endocan, IGFBPs, FGF acidic, vascular endothelial growth factor (VEGF), among many others were found upregulated in GL-261 conditioned medium. Nevertheless, a significant reduction in adiponectin, serpin E1 and TIMP-1 levels were observed in CGl $(p \leq 0.01)$.

\section{Conclusion}

Adipose tissue is defined as a lipid store depot, inflammatory and endocrine organ (Mendonça and Soares 2015). Thus, it provides a chronic low-grade inflammatory condition potentiated by the presence of multiple cytokines and hormones, sometimes associated with disease. Most part of these factors are known to play a role in cell proliferation, apoptosis, migration and invasiveness, as well as adhesion capacity, becoming expected to be overexpressed in conditioned medium. Recent findings point that inflammatory, angiogenic or metabolic factors, significantly influence tumor behavior (Hanahan and Weinberg 2011; Coelho et al. 2015). Taking into account in one hand the morbidity and the mortality associated to gliomas and on the other hand the increased prevalence of obesity and its possible role in cancer, studies that elucidate this relationship are of paramount importance in order to identify new glioma biomarkers, to grade specific protein signatures to provide treatment efficacy, and to identify novel effective drug targets against malignant glioma (Niclou et al. 2010).

In the current study we analyzed the proteome profile of a cellular model of brain cancer GL261 under the presence of adipocyte secretome. Our general results suggest an increase of viability, metabolic fitness, proliferation of tumor cell and reduced apoptosis. However, we are going to approach it by 
Table 1 Results retrieved for MALDI-TOF-MS/PMF queries in Mascot database search engine. Differential protein expression (> 2.0 fold upregulated and $<0.5$-fold down-regulated in $\mathrm{CGl} / \mathrm{NCGl}$ ) of a total of 192 protein spots

\begin{tabular}{|c|c|c|c|c|c|c|}
\hline Protein spot & $\begin{array}{l}\text { Mascot MOWSE } \\
\text { score }^{\text {a }}\end{array}$ & $\begin{array}{l}\mathrm{N} \text { matches } \\
\text { ( } \mathrm{n} \text { queries) }\end{array}$ & $\begin{array}{l}\% \text { sequence } \\
\text { coverage }^{\mathrm{b}}\end{array}$ & Ratio $^{c}$ & Protein ID & Function \\
\hline Spot- $1^{\mathrm{d}}$ & 69 & $14(43)$ & 14 & $2.32(\uparrow)$ & $\begin{array}{l}\text { Replication factor C } \\
\text { subunit (RFC1) }\end{array}$ & $\begin{array}{l}\text { Clamp loader in eurcarioric replication. Role } \\
\text { in maintaining the stability and the } \\
\text { integrity of the genome (47). }\end{array}$ \\
\hline Spot-2 & 80 & $25(122)$ & 25 & $2.91(\uparrow)$ & $\begin{array}{l}\text { Kinesin heavy chain } \\
\text { isoform 5C (KIF5C) }\end{array}$ & $\begin{array}{l}\text { Kinesin motor protein present in motor } \\
\text { neurons and associated with trafficking o } \\
\text { mitochondria and vesicles }(48,49) \text {. }\end{array}$ \\
\hline Spot-3 & 102 & $20(107)$ & 52 & $2.23(\uparrow)$ & Annexin A2 (ANXA2) & $\begin{array}{l}\text { Phospholipid-binding intracellular protein. } \\
\text { Involved in anti-inflammatory and } \\
\text { anticoagulation, cell proliferation and } \\
\text { differentiation and apoptosis (34-36). }\end{array}$ \\
\hline Spot-4 & 90 & $37(109)$ & 24 & $2.82(\uparrow)$ & $\begin{array}{l}\text { Nebulin-related-ancho- } \\
\text { ring protein (NRAP) }\end{array}$ & $\begin{array}{l}\text { Known for cytoskeletal stability, cell } \\
\text { migration and protein scaffolding }(50) \text {. }\end{array}$ \\
\hline Spot-5 & 125 & $14(67)$ & 53 & $2.07(\uparrow)$ & $\begin{array}{l}\text { Guanine } \\
\text { nucleotide-binding } \\
\text { protein subunit } \\
\text { beta-2-like 1 (RACK1) }\end{array}$ & $\begin{array}{l}\text { Intracellular adapter protein in } \\
\text { signal-tranuction pathways. Influences } \\
\text { cell proliferation, migration, adhesion and } \\
\text { spreading and protein synthesis }(51,52) \text {. }\end{array}$ \\
\hline Spot-6 & 100 & $18(68)$ & 35 & $0.33(\downarrow)$ & $\begin{array}{l}\text { Stress-induced } \\
\text { phosphoprotein } 1 \\
\text { (STI1) }\end{array}$ & $\begin{array}{l}\text { Co-chaperone in Hsp } 70 \text { and Hsp90 folding } \\
\text { and protein transcription, signal } \\
\text { transduction and cell division. Associatec } \\
\text { with cell proliferation and invasion (53). }\end{array}$ \\
\hline Spot-7 & 93 & $17(65)$ & 35 & $0.66(\downarrow)$ & $\begin{array}{l}\text { Heterogeneous nuclear } \\
\text { ribonucleoprotein L } \\
(\text { hnRNP L) }\end{array}$ & $\begin{array}{l}\text { Central role in RNA metabolism. Also } \\
\text { implicated in cell proliferation and } \\
\text { invasion }(54,55) \text {. }\end{array}$ \\
\hline Spot-8 & 93 & $21(128)$ & 61 & $0.4(\downarrow)$ & $\begin{array}{l}\text { Phosphoglycerate Kinase } \\
1 \text { (PGK1) }\end{array}$ & $\begin{array}{l}\text { Catayzes production one molecule of ATP } \\
\text { during glicose breackdown (56). }\end{array}$ \\
\hline Spot-9 & 110 & $14(72)$ & 48 & $\begin{array}{l}\text { Only in } \\
\text { NCG1 }\end{array}$ & Aldose reductase (AR) & $\begin{array}{l}\text { Metabolic reduction of glucose to sorbitol } \\
\text { and catalyzes reduction of ROS and lipic } \\
\text { peroxidation, increasing mutagenesis risk } \\
(57,58) \text {. }\end{array}$ \\
\hline Spot- $10^{\mathrm{e}}$ & 79 & $10(54)$ & 40 & $\begin{array}{l}\text { Only in } \\
\text { NCGl }\end{array}$ & Carbonic anhydrase (CA) & $\begin{array}{l}\text { Metalloenzyme participating in respiration, } \\
\text { calcification and acid-base balance. } \\
\text { Product of HIF- } 1 \alpha \text {, overexpressed in } \\
\text { hypoxic solid tumors }(59,60) \text {. }\end{array}$ \\
\hline Spot- $11^{\mathrm{d}}$ & 64 & $8(58)$ & 17 & $\begin{array}{l}\text { Only in } \\
\text { CGl }\end{array}$ & $\begin{array}{l}\text { Citrate synthase, } \\
\text { mitochondrial (CS) }\end{array}$ & $\begin{array}{l}\text { Catalyzes mytochondiral reactions and it is } \\
\text { considered to play role in cancer cells } \\
\text { metabolism regarding metabolic } \\
\text { reprogramming }(61,62) \text {. }\end{array}$ \\
\hline
\end{tabular}

\footnotetext{
${ }^{\text {a }}$ Scores greater than 77 are significant for $\mathrm{p}<0.01$

${ }^{\mathrm{b}}$ Represents the percentage of the protein's sequence represented by the peptides identified in the MS run

${ }^{\mathrm{c}}$ Ratio $=\mathrm{CGl} / \mathrm{NCGl}$ (CGl - conditioned glioma cells, NCGl - non-conditioned glioma cells)

${ }^{\mathrm{d}}$ Results obtained by limiting the research to entries from Mus musculus. In this case, scores greater than 62 are significant for $p<0.01$

${ }^{\mathrm{e}}$ Result obtained allowing up to 2 missed cleavages
}

focusing on their relationship within inflammation and angiogenesis.

The proteomic analysis has allowed the identification of eleven well differentiated proteins that are secreted by 3T3L1 adipocytes with a potential role in cancer biology. The molecular, biochemical and physiological characteristics of the differentially expressed proteins are summarized in Table 1.
Our findings revealed lower expression of STI1, hnRNP L and PGK1 when glioma cells were exposed to mature adipocytes conditioned medium. Regarding multiple effects of STI1, hnRNPs and PGK1 this under expression might reflect that the adipokines secreted by mature adipocytes might be able to stop some important pathways in carcinogenesis, complemented with remodeling the oxidative metabolism toward the utilization of fatty acids substrates instead of glucose. 


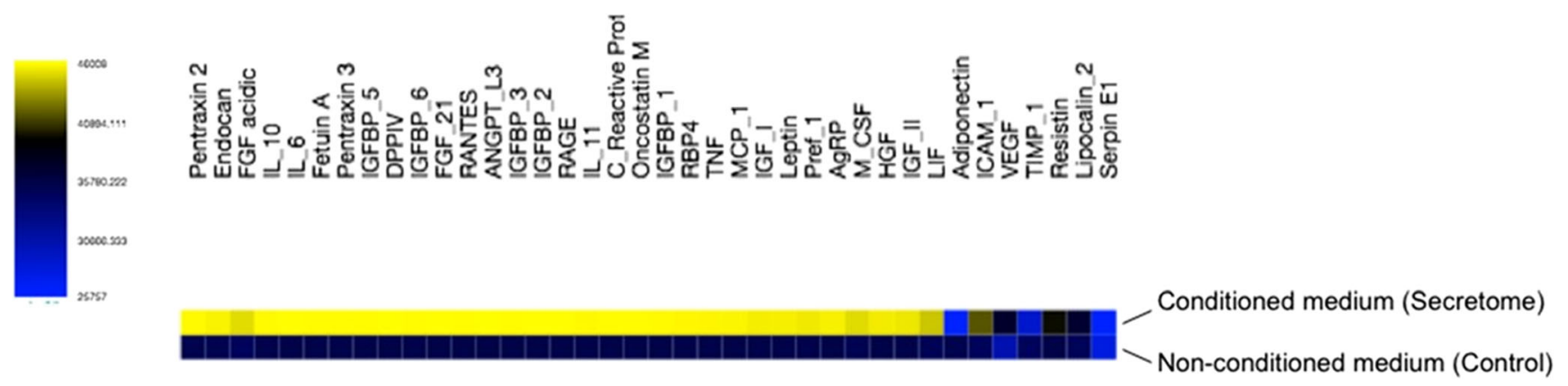

Fig. 1 Expression proteomic profile of GL261 with and without the effect of the secretome of 3T3-L1 mature adipocyte cells

This interpretation may be further supported by the increased expression of mitochondrial citrate synthase. Also, proteome array profiling reveals under expression of TIMP-1, an inhibitor of ECM degradation, Serpin E1 and adiponectin significant downregulation in conditioned medium, supporting adipokine results of carcinogenesis development by adipocytes.

Additionally, data revealed that aldose reductase and carbonic anhydrase were present only in glioma cells and that their expression was completely blocked when glioma cells were exposed to mature adipocytes conditioned medium. Our findings suggested that this blockage may reflect a total inhibition of aldose reductase and carbonic anhydrase, possibly associated to oxidative stress response prevention, inhibition of inflammation and cancer proliferation, angiogenesis and carcinogenesis, which may suggest some kind of protective mechanism related to obesity.

Considering overexpressed proteins in conditioned medium, RFC1, KIF5C, ANXA2, NRAP, RACK1 results were supported by overexpression of almost all the proteins profiled by arrays, comprising angiogenesis, growth, metabolic and hormonal functions. Our analysis revealed that ANXA2 expression ( 2.23 fold) was more pronounced when glioma cells were exposed to CGl. This finding is in agreement with previous studies that also revealed that ANXA2 is elevated in glioma, in which it plays a central role in cell motility, migration, invasion and angiogenesis (Lokman et al. 2011; Zhai et al. 2011; Zhang et al. 2012).

Moreover, and considering proteome array profiling, endocan, which is a proteoglycan secreted by endothelial cells and upregulated by proangiogenic factors, appears to be overexpressed in tumour vessels (Maurage et al. 2009; Matano et al. 2014). Considering its overexpression in CGl, it may explain the involvement of adipose tissues in tumor aggressiveness. In addition, adipose tissue contains diverse cells types including adipose stromal cells, which produce a myriad of angiogenic factors, VEGF, HGF, FGF-2, and TGF, contributing to the increment of released angiogenic and growth factor cytokines.

Thru microarray analysis we further identified the factors that are released by adipocyte cells, and revealed that several pro-inflammatory factors (IL-6, IL-11, LIF, PAI-1, TNF- $\alpha$ ), metabolic markers (FGF-21, IGFBPs), angiogenic growth factors (endocan, HGF, VEGF IGF-I), and hormones (leptin, resistin, RBP-4) were secreted to the medium into a high extent, whereas TIMP-1, an inhibitor of ECM degradation, SerpinE1, which encodes Plasminogen Activator Inhibitor 1 (PAI-1), were under expressed on CGl. Adiponectin, as it was expectable, was significantly downregulated in CGl medium when compared with NCGl. Adiponectin modulates inflammatory responses, energy expenditure in the CNS and periphery, glucose regulation and fatty acid catabolism. Its circulating levels inversely correlate with insulin resistance, metabolic syndrome, obesity and cardiovascular diseases. Curiously, different hormones related with insulin resistance and obesity, including TNF- $\alpha$ and IL-6, downregulate adiponectin expression and secretion in fat cells in vitro (Cao 2013; Donohoe et al. 2016). Our results on TNF- $\alpha$ (adipocytokine implicated in inflammation, apoptosis and cell survival), IL-6 (related to proliferation in human glioblastoma cases, leading to poor prognosis) and IL-11, corroborate these inverse relationship with adiponectin (Hossain et al. 2015).

Endocan, as well as FGF-21, are extensively present along with proinflammatory and proangiogenic molecules. It is associated with a vast number of pathological conditions where endothelium gets highly vascularized cancers, making it a likely marker of the vascular growth and angiogenesis during cancer evolution (Delehedde et al. 2013),(Aoki et al. 2002). These data support our findings in which endocan is overexpressed in CGl. Moreover, and regarding other growth factors, FGF-21, HGF and IGFBPs, they all were overexpressed in CGl. Hepatocyte Growth Factor (HGF), a multifunctional trophic factor activates a tyrosine kinase signaling cascade, is elevated in obese adults and adolescents. In vitro, HGF secretion from adipocytes of obese compared to lean individuals is greater (Cao 2013; Kiliaan et al. 2014).

Development and basic functions of organs and tissues relay on angiogenesis, and angiogenesis role in adipose tissue development and obesity is crucial. Additionally, a great number of studies point that an insufficiency in adipose tissue angiogenesis contributes to metabolic disease in obesity (Lemoine et al. 2013; Corvera and Gealekman 2014). These 
data from the literature reinforce our findings concerning the effect of conditioned medium from adipose tissue in augmenting GL261 cell proliferation, migration, ability to invade and decreasing apoptosis (Fig. 2).

Finally, bioinformatic cancer tools were used for better understand if the genes and proteins found in our animal model affected by the molecules secreted by adipocytes could also be involved in human cancer. First, we queried the Brain Lower Grade Glioma cohort database from The Cancer Genome Atlas (TCGA-LGG project) concerning 516 human subjects using the over-expressed and down-regulated genes found in our microarray studies. A total of 8 cases $(3$ males and 5 females) with 15 somatic mutations (mainly substitutions) in 7 of the 10 query genes were found (SERPINE1, IL10, ICAM1, PITX2, ESM1, RETN and TIMP1) revealing that they might be somehow implicated in the human cancer. However, a larger sample size will be required to find statistically significant effects and to conjecture the impact of these genes/mutations in glioma overall survival and aggressiveness. Then using the same set of over- and down-regulated genes it was performed an analysis in the REACTOME in order to understand the involvement of the orthologous proteins in human pathways. The cross-reference of the several differentially expressed markers of glioma under the effect of the molecules secreted by adipocytes by REACTOME has result in an outcome involving scientifically more than 25 human pathways (Supplementary Data). In brief, the adipocytes' secretome may influence mainly cancer signaling transduction, immune/inflammatory, disease (cancer) gene transcription and extracellular matrix organization human pathways (Fig. 3).

\section{Concluding remarks}

In conclusion, the present study presents a paradoxical relationship between obesity and cancer (Fig. 3). In a first view, conditioned medium (adipokines-enriched medium) may present a protective effect against glioma, since STI1, hnRNPs and PGK1 that are generally overexpressed in several types of cancer are under expressed. Similarly, both carbonic anhydrase and aldose reductase that play an important role in cell physiology, inflammation and cancer metabolism are even suppressed in glioma cells that grown under adipokinesenriched environment.

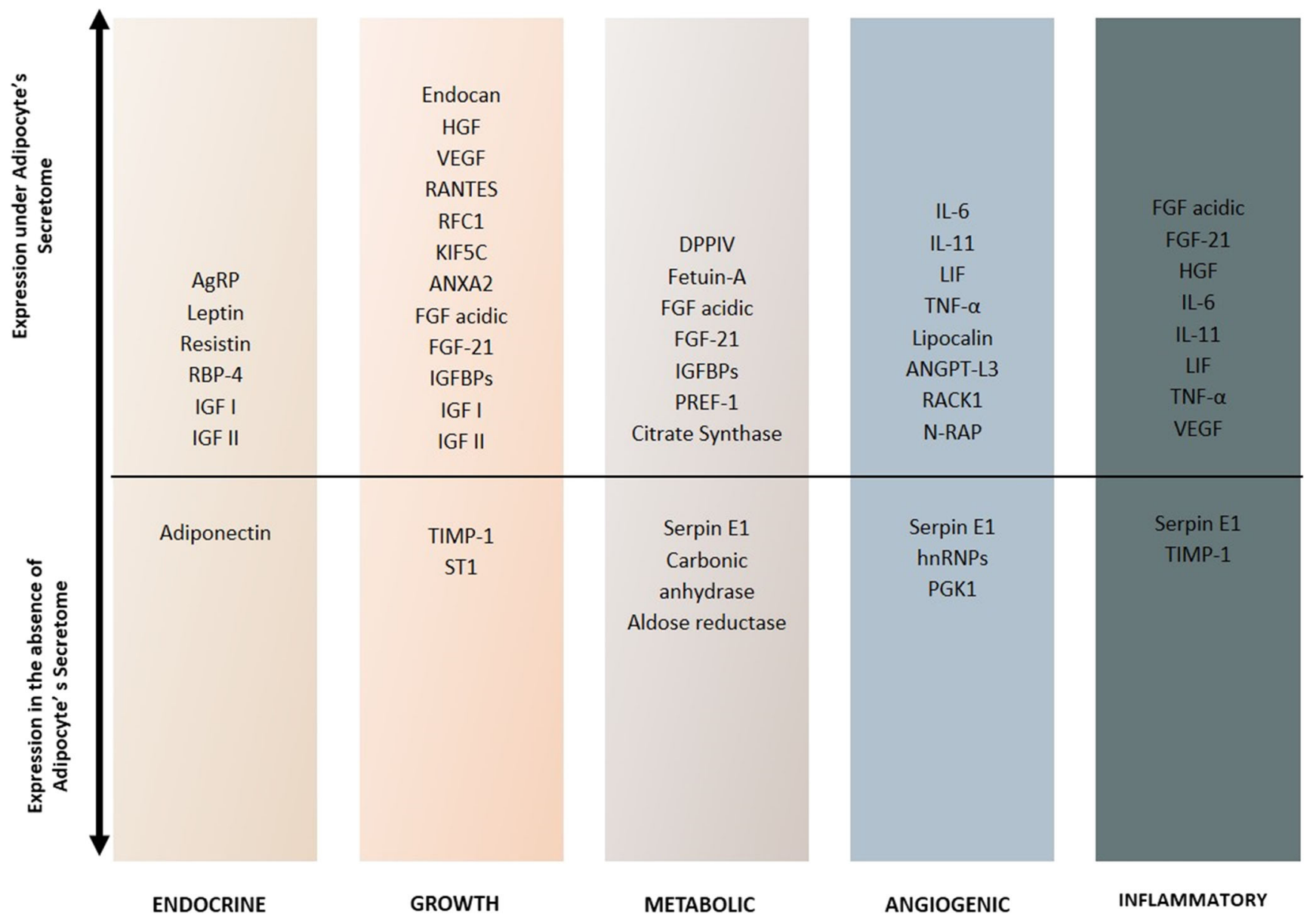

Fig. 2 Proposed classification of molecules analyzed by microarrays considering its cellular and molecular functions. According to over and underexpression in different contexts 


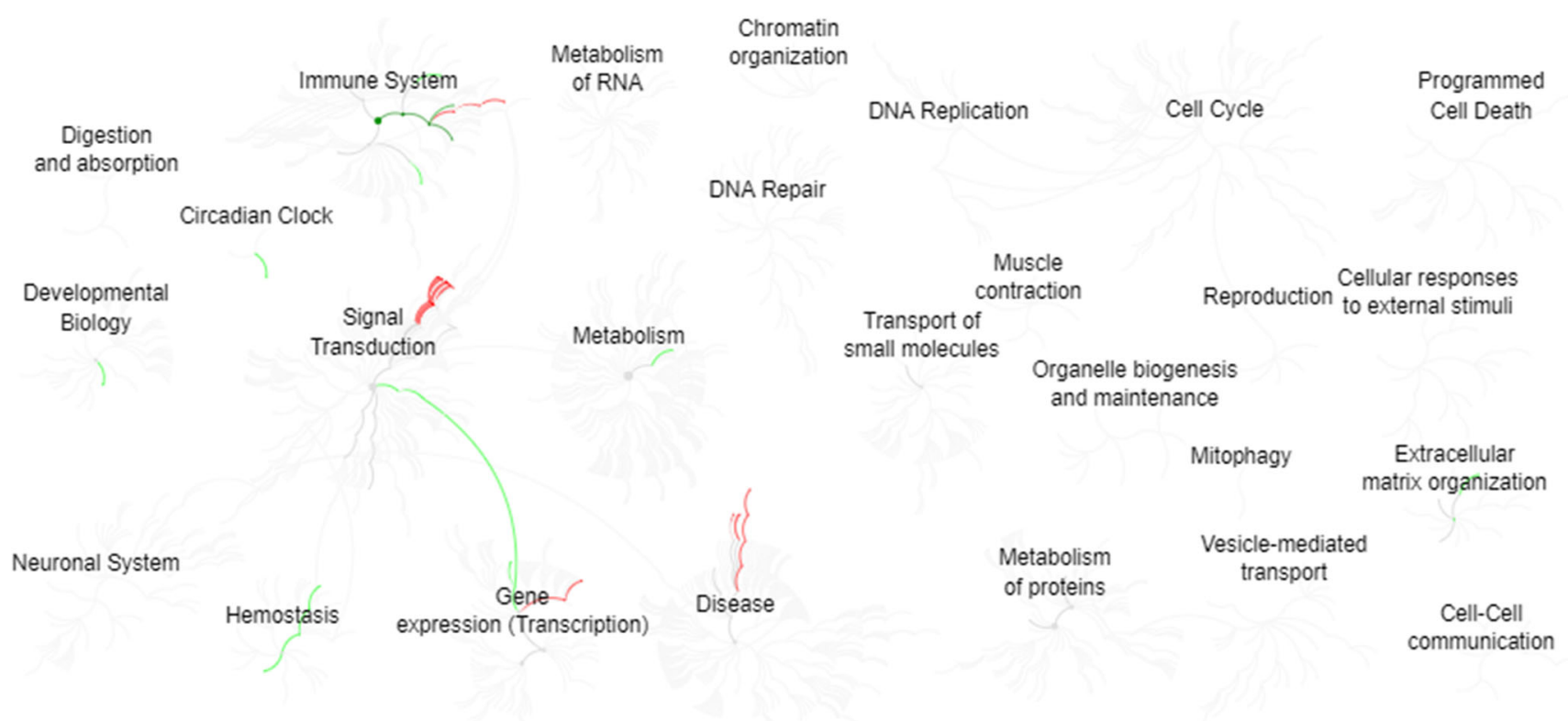

Fig. 3 REACTOME diagram for human ortholog gene pathways. This figure shows a genome-wide overview regarding the pathways of glioma altered by adipocyte secretome. Adipocyte secretome influences immune/ inflammatory signaling pathways in human glioma cancer cells. The grey

color code signifies pathways that are not significantly over-represented. Red and green colors denote significant $(p<0,05)$ pathways under- and over-represented respectively

Contrariwise, RFC1, KIF5C, ANXA2, N-RAP and RACK1 that are generally involved in the matrix remodeling, proliferation, migration, invasion of cancer cells is overexpressed in GL261 cell the in the presence of the adipokines-enriched medium. Furthermore, along with these and CG1, and as long as we can observe on protein secretome assay, our results unfolded the damaging effects of adipocytes secretome towards glioma aggressiveness. Also, the presence of citrate synthase only in glioma cells cultured under

conditioned medium and the decreased expression of PGK1 supports the non-tested hypothesis that under an obesity environment, glioma cells may reshuffle their metabolic patterns towards increased lipid consumption for aerobic ATP production over glucose and other simple sugars.

Furthermore, our MALDI-TOF and proteomic array data suggests that, on a primary phase, obesity contributes for decreasing of the tumor initiation. Even though, as time goes by, studied growth factors positively influence proliferation and

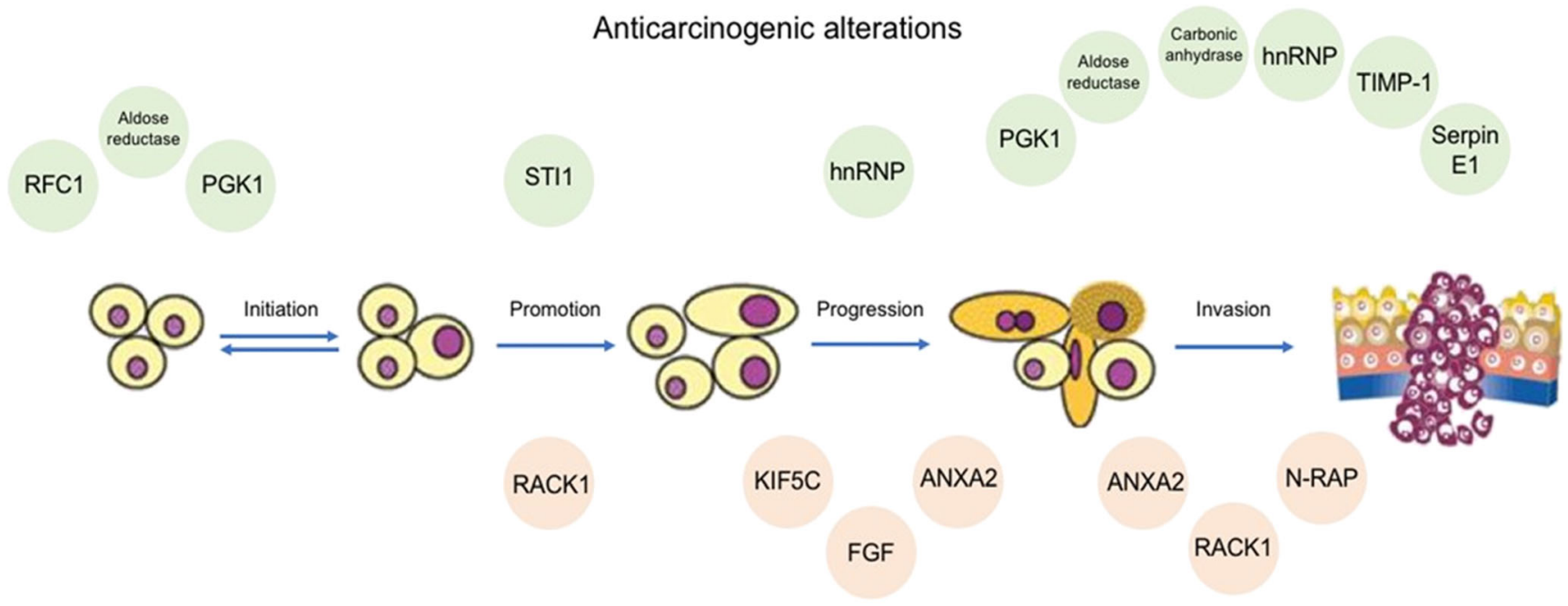

\section{Procarcinogenic alterations}

Fig. 4 Influence of adipocyte secretome in glioma tumorigenesis. Under the influence of the adipocyte secretome some proteomic alterations promote tumorigenesis (pink circles) and while other alterations seem to be protective (green circles) 
restricted tumorigenic growth. However, as we can observe from diminished growth and hypoxic factors, and different metalloproteases, suggesting that previously tumor proliferation due to obesity are restricted and confined, not metastizing. As stated previously, two important studies have recognized that obesity has no clear relationship with the occurrence of glioma (Wiedmann et al. 2017; Disney-Hogg et al. 2018). Thus, our data reinforce that idea on obesity as no relation to glioma and some of the secreted adipokine might even be protective against glioma initiation and metastization (Fig. 4). However, once the tumor is stablished, at least some adipokines might be involved in other stages of carcinogenesis as summarized in Fig. 4.

Finally, use mouse glioma C57Bl/6 J as a glioma in vivo model as long as we may growth their cell in vitro for post in vivo inoculation. This way we may study tissue behavior in response to cancer cells using a peer-reviewed validated animal model (Szatmari et al. 2006; Candolfi et al. 2007; Lawrence et al. 2012; Sielska et al. 2013; YI et al. 2013; Xu et al. 2014).

This study undoubtedly requires additional work to fulfill our understanding on the implication of adipocytes in malignant brain tumors biology. Meanwhile, it discloses an interesting in vitro model for the study of glioma biology under a "obesity" environment, that can be explored for the understanding of cancer cells biology, for the search of biomarkers, prognostic markers and therapeutic approaches.

\section{References}

Aoki T, Kato S, Fox JC, Okamoto K, Sakata K, Morimatsu M, Shigemori M (2002) Inhibition of autocrine fibroblast growth factor signaling by the adenovirus-mediated expression of an antisense transgene or a dominant negative receptor in human glioma cells in vitro. Int $\mathrm{J}$ Oncol 21:629-636

Bainbridge MN, Armstrong GN, Gramatges MM et al (2014) Germline mutations in Shelterin complex genes are associated with familial glioma. JNCI J Natl Cancer Inst 107: dju384-dju384. https://doi.org/10.1093/jnci/dju384

Benson VS, Pirie K, Green J et al (2008) Lifestyle factors and primary glioma and meningioma tumours in the million women study cohort. Br J Cancer 99:185-190. https://doi.org/10.1038/sj.bjc. 6604445

Calle EE, Thun MJ (2004) Obesity and cancer. Oncogene 23:6365-6378. https://doi.org/10.1038/sj.onc.1207751

Calle EE, Thun MJ, Petrelli JM, Rodriguez C, Heath CW Jr (1999) Body-mass index and mortality in a prospective cohort of U.S. adults. N Engl J Med 341:1097-1105. https://doi.org/10.1056/NEJM199910073411501

Candolfi M, Curtin JF, Nichols WS, Muhammad AKMG, King GD, Pluhar GE, McNiel EA, Ohlfest JR, Freese AB, Moore PF, Lerner J, Lowenstein PR, Castro MG (2007) Intracranial glioblastoma models in preclinical neuro-oncology: neuropathological characterization and tumor progression. J Neuro-Oncol 85:133-148. https://doi.org/10.1007/s11060007-9400-9

Cao Y (2013) Angiogenesis and vascular functions in modulation of obesity, adipose metabolism, and insulin sensitivity. Cell Metab 18:478-489. https://doi.org/10.1016/j.cmet.2013.08.008

Carmeliet P (2003) Angiogenesis in health and disease. Nat Med 9:653660. https://doi.org/10.1038/nm0603-653

Chen J, McKay RMM, Parada LFF (2012) Malignant glioma: lessons from genomics, mouse models, and stem cells. Cell 149:36-47. https://doi.org/10.1016/j.cell.2012.03.009

Coelho P, Almeida J, Prudêncio C, Fernandes R, Soares R (2015) Effect of adipocyte Secretome in melanoma progression and Vasculogenic mimicry. J Cell Biochem 117:1697-1706. https://doi.org/10.1002/ jcb. 25463

Corvera S, Gealekman O (2014) Adipose tissue angiogenesis: impact on obesity and type-2 diabetes. Biochim Biophys Acta 1842:463-472. https://doi.org/10.1016/j.bbadis.2013.06.003

Costa C, Soares R, Schmitt F (2004) Angiogenesis: now and then. APMIS 112:402-412. https://doi.org/10.1111/j.1600-0463.2004. apm11207-0802.x

Costa C, Incio J, Soares R (2007) Angiogenesis and chronic inflammation: cause or consequence? Angiogenesis 10:149166. https://doi.org/10.1007/s10456-007-9074-0

Delehedde M, Devenyns L, Maurage C-A, Vivès RR (2013) Endocan in cancers: a lesson from a circulating dermatan sulfate proteoglycan. Int J Cell Biol 2013:705027. https://doi.org/10.1155/2013/705027

Disney-Hogg L, Sud A, Law PJ, Cornish AJ, Kinnersley B, Ostrom QT, Labreche K, Eckel-Passow JE, Armstrong GN, Claus EB, Il'yasova D, Schildkraut J, Barnholtz-Sloan JS, Olson SH, Bernstein JL, Lai RK, Swerdlow AJ, Simon M, Hoffmann P, Nöthen MM, Jöckel KH, Chanock S, Rajaraman P, Johansen C, Jenkins RB, Melin BS, Wrensch MR, Sanson M, Bondy ML, Houlston RS (2018) Influence of obesityrelated risk factors in the aetiology of glioma. Br $\mathrm{J}$ Cancer 118:1020-1027. https://doi.org/10.1038/s41416-018-0009-x

Donohoe CL, Lysaght J, O 'sullivan J, Reynolds J V (2016) Emerging concepts linking obesity with the hallmarks of cancer. https://doi.org/10.1016/j.tem.2016.08.004 
Fabregat A, Jupe S, Matthews L, Sidiropoulos K, Gillespie M, Garapati P, Haw R, Jassal B, Korninger F, May B, Milacic M, Roca CD, Rothfels K, Sevilla C, Shamovsky V, Shorser S, Varusai T, Viteri G, Weiser J, Wu G, Stein L, Hermjakob H, D'Eustachio P (2018) The Reactome pathway knowledgebase. Nucleic Acids Res 46: D649-D655. https://doi.org/10.1093/nar/gkx1132

Gundry RL, White MY, Murray CI et al (2009) Preparation of proteins and peptides for mass spectrometry analysis in a bottom-up proteomics workflow. Curr Protoc Mol Biol Chapter 10:10.25.1-10.25.23. https://doi.org/10.1002/0471142727.mb1025s88

Hanahan D, Weinberg RA (2011) Hallmarks of cancer: the next generation. Cell 144:646-674. https://doi.org/10.1016/j.cell.2011.02.013

Hossain A, Gumin J, Gao F, Figueroa J, Shinojima N, Takezaki T, Priebe W, Villarreal D, Kang SG, Joyce C, Sulman E, Wang Q, Marini FC, Andreeff M, Colman H, Lang FF (2015) Mesenchymal stem cells isolated from human gliomas increase proliferation and maintain stemness of glioma stem cells through the IL-6/gp130/STAT3 pathway. Stem Cells 33: 2400-2415. https://doi.org/10.1002/stem.2053

Huse JT, Holland E, DeAngelis LM (2013) Glioblastoma: molecular analysis and clinical implications. Annu Rev Med 64:59-70. https://doi.org/10.1146/annurev-med-100711-143028

Khandekar MJ, Cohen P, Spiegelman BM (2011) Molecular mechanisms of cancer development in obesity. Nat Rev Cancer 11:886-895. https://doi.org/10.1038/nrc3174

Kiliaan AJ, Arnoldussen IA, Gustafson DR (2014) Adipokines: a link between obesity and dementia? IArnoldussen@anatumcnnl. Lancet Neurol 13:913-923. https://doi.org/10.1016/S1474-4422(14) 70085-7

Lawrence JE, Cook NJ, Rovin RA, Winn RJ (2012) Leptin Promotes Glioblastoma. Neurol Res Int 2012:1-6. https://doi.org/10.1155/ 2012/870807

Lemoine AY, Ledoux S, Larger E (2013) Adipose tissue angiogenesis in obesity. Thromb Haemost 110:661-669. https://oi.org/10.1160/ TH13-01-0073

Lijnen HR (2008) Angiogenesis and obesity. Cardiovasc Res 78:286293. https://doi.org/10.1093/cvr/cvm007

Lokman NA, Ween MP, Oehler MK, Ricciardelli C (2011) The role of annexin A2 in tumorigenesis and cancer progression. Cancer Microenviron 4:199-208. https://doi.org/10.1007/ s12307-011-0064-9

Luisa A, Stefano D, Enciso-mora V, et al (2012) Association between glioma susceptibility molecular etiologies. 1-6

Matano F, Yoshida D, Ishii Y, Tahara S, Teramoto A, Morita A (2014) Endocan, a new invasion and angiogenesis marker of pituitary adenomas. J Neuro-Oncol 117:485-491. https://doi.org/10.1007/s11060-014-1377-6

Maurage C-A, Adam E, Minéo J-F, Sarrazin S, Debunne M, Siminski RM, Baroncini M, Lassalle P, Blond S, Delehedde M (2009) Endocan expression and localization in human glioblastomas. J Neuropathol Exp Neurol 68:633-641. https://doi.org/10.1097/ NEN.0b013e3181a52a7f

Mendonça F, Soares R (2015) Obesity and cancer phenotype: is angiogenesis a missed link? Life Sci 139:16-23. https://doi.org/10.1016/j. Ifs.2015.08.009

Moore SC, Rajaraman P, Dubrow R, Darefsky AS, Koebnick C, Hollenbeck A, Schatzkin A, Leitzmann MF (2009) Height, body mass index, and physical activity in relation to glioma risk. Cancer Res 69:8349-8355. https://doi.org/10.1158/00085472.CAN-09-1669

Niclou SP, Fack F, Rajcevic U (2010) Glioma proteomics: status and perspectives. J Proteome 73:1823-1838. https://doi.org/10.1016/j. jprot.2010.03.007
Ostrom QT, Bauchet L, Davis FG, Deltour I, Fisher JL, Langer CE, Pekmezci M, Schwartzbaum JA, Turner MC, Walsh KM, Wrensch MR, Barnholtz-Sloan JS (2014) The epidemiology of glioma in adults: a "state of the science" review. Neuro-Oncology 16:896-913. https://doi.org/10.1093/ neuonc/nou087

Parkin DM, Bray F, Ferlay J, Pisani P (2002) Global cancer statistics. CA Cancer J Clin 55:74-108

Patrick W, Kesari S (2008) Malignant Gliomas in Adults. N Engl J Med 359:492-507. https://doi.org/10.1056/NEJMc086380

Pirraco A, Coelho P, Rocha A, Costa R, Vasques L, Soares R (2010) Imatinib targets PDGF signaling in melanoma and host smooth muscle neighboring cells. J Cell Biochem 111:433-441. https:// doi.org/10.1002/jcb. 22725

Pi-Sunyer FX (2002) The obesity epidemic: pathophysiology and consequences of obesity. Obes Res 10(Suppl 2):97S-104S. https://doi. org/10.1038/oby.2002.202

Prieto-Hontoria PL, Pérez-Matute P, Fernández-Galilea M, Bustos M, Martínez JA, Moreno-Aliaga MJ (2011) Role of obesity-associated dysfunctional adipose tissue in cancer: a molecular nutrition approach. Biochim Biophys Acta 1807:664-678. https://doi.org/10. 1016/j.bbabio.2010.11.004

Roberts DL, Dive C, Renehan AG (2010) Biological mechanisms linking obesity and cancer risk: new perspectives. Annu Rev Med 61:301-316. https://doi.org/10.1146/ annurev.med.080708.082713

Rosenfeld J, Capdevielle J, Guillemot JC, Ferrara P (1992) In-gel digestion of proteins for internal sequence analysis after one- or twodimensional gel electrophoresis. Anal Biochem 203:173-179. https://doi.org/10.1016/0003-2697(92)90061-B

Shevchenko A, Tomas H, Havlis J et al (2006) In-gel digestion for mass spectrometric characterization of proteins and proteomes. Nat Protoc 1:2856-2860. https://doi.org/10.1038/nprot.2006.468

Siegel EM, Nabors LB, Thompson RC, Olson JJ, Browning JE, Madden MH, Han G, Egan KM (2013) Prediagnostic body weight and survival in high grade glioma. J Neuro-Oncol 114:79-84. https://doi. org/10.1007/s11060-013-1150-2

Sielska M, Przanowski P, Wylot B, Gabrusiewicz K, Maleszewska M, Kijewska M, Zawadzka M, Kucharska J, Vinnakota K, Kettenmann H, Kotulska K, Grajkowska W, Kaminska B (2013) Distinct roles of CSF family cytokines in macrophage infiltration and activation in glioma progression and injury response. J Pathol 230:310-321. https://doi.org/10.1002/path.4192

Szatmari T, Lumniczky K, Desaknai S, Trajcevski S, Hidvegi EJ, Hamada H, Safrany G (2006) Detailed characterization of the mouse glioma 261 tumor model for experimental glioblastoma therapy. Cancer Sci 97:546-553. https://doi.org/10.1111/j.1349-7006.2006. 00208.x

van Kruijsdijk RCM, van der Wall E, Visseren FLJ (2009) Obesity and Cancer: the role of dysfunctional adipose tissue. Cancer Epidemiol Biomark Prev 18:2569-2578. https://doi.org/10.1158/1055-9965. EPI-09-0372

Verpelli C, Bertani G, Cea V, Patti M, Bikfalvi A, Bello L, Sala C (2010) Anti-angiogenic therapy induces integrin-linked kinase 1 upregulation in a mouse model of glioblastoma. PLoS One 5:1-12. https://doi.org/10.1371/journal.pone.0013710

Wiedmann MKH, Brunborg C, Di Ieva A et al (2017) Overweight, obesity and height as risk factors for meningioma, glioma, pituitary adenoma and nerve sheath tumor: a large population-based prospective cohort study. Acta Oncol (Madr) 56:1302-1309. https://doi.org/ 10.1080/0284186X.2017.1330554

Wolin KY, Carson K, Colditz G a (2010) Obesity and Cancer. Oncologist 15:556-565. https://doi.org/10.1634/theoncologist.2009-0285 
Xu M, Yao Y, Hua W, Wu Z, Zhong P, Mao Y, Zhou L, Luo F, Chu Y (2014) Mouse glioma immunotherapy mediated by A2B5+ GL261 cell lysate-pulsed dendritic cells. J Neuro-Oncol 116:497-504. https://doi.org/10.1007/s11060-013-1334-9

Yi L, Zhou C, Wang B et al (2013) Implantation of GL261 neurospheres into C57/BL6 mice: a more reliable syngeneic graft model for research on glioma-initiating cells. Int J Oncol 43:477-484. https://doi.org/10.3892/ijo.2013.1962

Yin J, Gao Z, He Q, Zhou D, Guo ZK, Ye J (2008) Role of hypoxia in obesity-induced disorders of glucose and lipid metabolism in adipose tissue. AJP Endocrinol Metab 296:E333-E342. https://doi.org/ 10.1152/ajpendo.90760.2008

Young N, Van Brocklyn JR (2007) Roles of sphingosine-1-phosphate (S1P) receptors in malignant behavior of glioma cells. Differential effects of S1P2 on cell migration and invasiveness. Exp Cell Res 313:1615-1627. https://doi.org/10.1016/j.yexcr.2007.02.009

Zhai H, Acharya S, Gravanis I, Mehmood S, Seidman RJ, Shroyer KR, Hajjar KA, Tsirka SE (2011) Annexin A2 promotes glioma cell invasion and tumor progression. J Neurosci 31:14346-14360. https://doi.org/10.1523/JNEUROSCI.3299-11.2011

Zhang X, Liu S, Guo C, Zong J, Sun MZ (2012) The association of annexin A2 and cancers. Clin Transl Oncol 14:634-640. https://doi.org/10.1007/s12094-012-0855-6 